\title{
EVALUATION OF SAGE BIOMASS INDICATORS (Salvia officinalis L.) FOR ENERGY PRODUCTION AND THEIR RELATIONSHIP
}

\author{
Adi Shamku ${ }^{1 *}$, Andonaq Londo Lamani ${ }^{2}$ \\ ${ }^{1 *}$ Agriculture University of Tirana, Albania; \\ ${ }^{2}$ Polytechnic University of Tirana, Albania; \\ *Corresponding author Adi Shamku, e-mail: shamkua@yahoo.it;
}

Received June 2019; Accepted August 2019; Published September 2019;

DOI: https://doi.org/10.31407/ijees9412

\begin{abstract}
One of the major problems of our society is the energy crisis and the environmental crisis. Humanity has found ways to change one form of energy to another to serve itself. For example, we turn wood into heat when we burn it. Wood, a form of biomass, has been the first source of energy. In the sense of biomass energy, the term refers to those plants, residues and other biological materials that can be used as a fossil fuel substitute in the production of energy and other products. The living biomass takes up carbon as it grows and releases this carbon when used for energy, which is a neutral carbon cycle, meaning it does not increase the atmospheric concentration of greenhouse gases. So biomass is the sun's energy stored by plants through the process of photosynthesis. When we use energy from biomass, we use energy that originally comes from the Sun. To find an alternative source of energy production, we studied sage biomass (Salvia officinalis L.) as a case study. According to our analysis, sage biomass can be used effectively for energy production.
\end{abstract}

Keywords: Biomass, renewable energy, low calorific power, net incoming energy, net incoming power. 